\title{
The Effectiveness of Unconventional Monetary Policy: The Term Auction Facility
}

Daniel L. Thornton

\begin{abstract}
This paper investigates the effectiveness of one of the Federal Reserve's unconventional monetary policy tools, the term auction facility (TAF). At issue is whether the TAF reduced the spread between the London interbank offered rate (LIBOR) rates and equivalent-term Treasury rates by reducing the liquidity premium embedded in LIBOR rates. This paper suggests that rather than reducing the liquidity premium in LIBOR rates, the announcement of the TAF increased the risk premium in financial and other bond rates because market participants interpreted the announcement by the Fed and other central banks as a sign that the financial crisis was worse than previously thought. Evidence is presented that supports this hypothesis. (JEL E52, E58, G14)
\end{abstract}

Federal Reserve Bank of St. Louis Review, November/December 2011, 93(6), pp. 439-53.

\section{BACKGROUND}

T he Federal Reserve's actions in the wake of the financial crisis have spurred research into the effectiveness of unconventional monetary policy. One unconventional policy that has received considerable attention is the term auction facility (TAF). At issue is whether the TAF reduced the spread between the London interbank offered rate (LIBOR) rates and equivalent-term Treasury or overnight indexed swap (OIS) rates. The Fed introduced the TAF based on the belief that the increase in the spreads between term LIBOR rates and equivalent-term Treasury or OIS rates at the onset of the financial crisis was due to an increase in the liquidity premium in the interbank market. In announcing the TAF the Fed noted that, by allowing the Federal Reserve to inject term funds through a broader range of counterparties and against a broader range of collateral than traditional open market operations, this facility could help promote the efficient dissemination of liquidity when the unsecured interbank markets are under stress. ${ }^{1}$ In testimony before Congress on January 17, 2008, Chairman Bernanke (2008) indicated that the goal of the TAF was to reduce the incentive for banks to hoard cash and increase their willingness to provide credit to households and firms. That is, the Fed believed banks were hoarding liquidity. Consequently, the increase in the LIBOR spreads was a result of an increase in a liquidity premium that banks were requiring to lend in the interbank market. Christensen, Lopez, and Rudebusch (2009, p. 2; hereafter CLR) summarize the intended effectiveness of the TAF:

In theory, the provision of central bank liquidity could lower the liquidity premium on interbank debt through a variety of channels. On the supply side, banks that have a greater assurance of meeting their own unforeseen liquidity needs over time should be more willing to extend term loans to other banks. In addition, creditors should also be more willing to provide funding to banks that have easy and dependable access to funds, since there is a

1 Board of Governors of the Federal Reserve System (2007).

Daniel L. Thornton is a vice president and economic adviser at the Federal Reserve Bank of St. Louis.

(C) 2011, The Federal Reserve Bank of St. Louis. The views expressed in this article are those of the author(s) and do not necessarily reflect the views of the Federal Reserve System, the Board of Governors, or the regional Federal Reserve Banks. Articles may be reprinted, reproduced, published, distributed, displayed, and transmitted in their entirety if copyright notice, author name(s), and full citation are included. Abstracts, synopses, and other derivative works may be made only with prior written permission of the Federal Reserve Bank of St. Louis. 


\section{Figure 1}

Daily Spread Between the 3-Month LIBOR and T-Bill Rates (January 2, 2007-December 31, 2009)

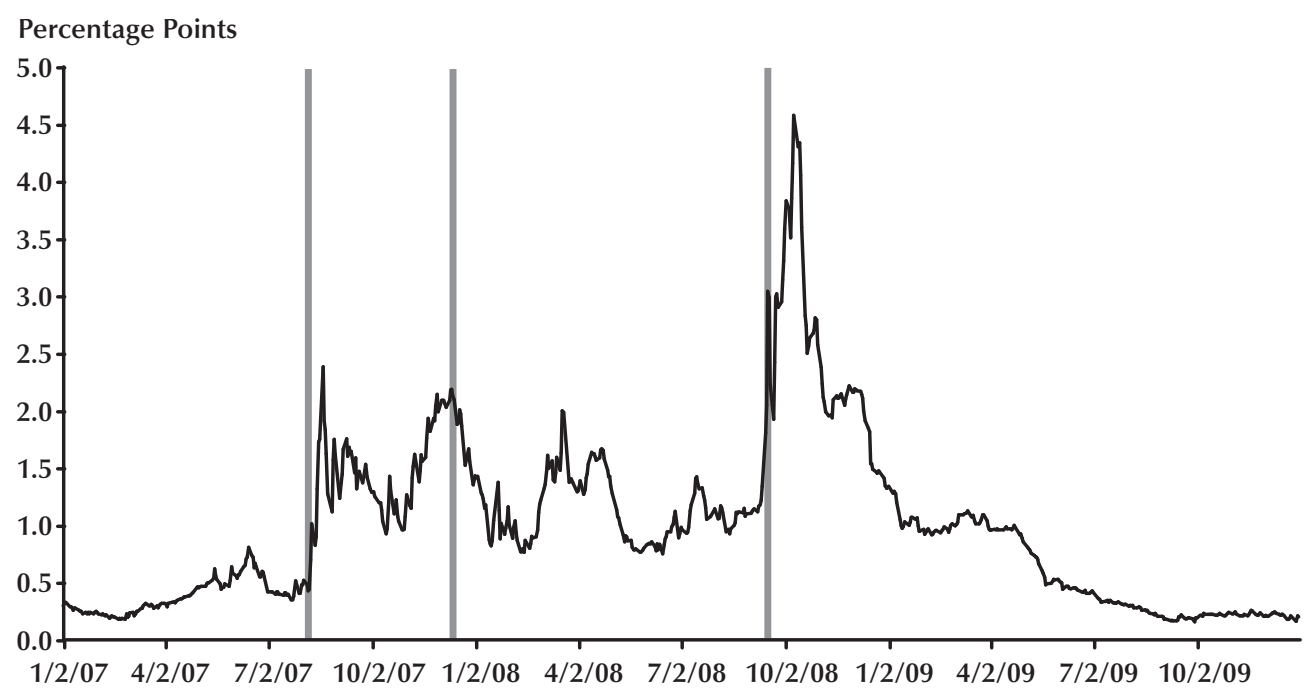

greater reassurance of timely repayment. On the demand side, with a central bank liquidity backstop, banks should be less inclined to borrow from other banks to satisfy any precautionary demand for liquid funds because their future idiosyncratic demands for liquidity over time can be met via the backstop.

To understand the issue, it is useful to consider Figure 1, which shows the daily spread between the 3-month LIBOR and Treasury bill rates from January 2, 2007, through December 31, 2009. The three vertical lines denote the dates of three important events: August 9, 2007, when BNP Paribas, France's largest bank, halted redemption on three investment funds (the financial crisis is assumed to begin on this date); December 12, 2007, when the Fed announced the TAF; and September 15, 2008, when Lehman Brothers filed for Chapter 11 bankruptcy protection. ${ }^{2}$ The spread began increasing in March 2007, on news of problems with subprime loans in the mortgage market, to a peak of 80 basis points in late June 2007 and then declined. The spread increased dramatically

2 For a complete time line of events during the financial crisis, see http://timeline.stlouisfed.org/index.cfm?p=timeline\#. at the outset of the financial crisis to a peak of about 240 basis points, declined again, and increased again to a peak of nearly 220 basis points on December 12, 2007; it then declined dramatically following the TAF announcement to a cyclical low of about 80 basis points in midJanuary 2008. From January 17, 2008, through September 14, 2008, the spread averaged 112 basis points. The spread increased dramatically again on Lehman's announcement, to a peak of 452 basis points on October 10, 2008, and then declined, eventually reaching pre-financial-crisis levels in the latter half of 2009.

The Fed argued that the dramatic increase in spreads in August 2007 reflected an increase in banks' liquidity premium - that is, banks were demanding a higher rate on interbank lending because of an increased demand for liquidity. Taylor and Williams (2008a,b, 2009) and others have argued that the increase in the interbank rate spreads was due to an increase in the risk premium rather than an increase in a liquidity premium. If the increase in the LIBOR/T-bill spreads was the consequence of an increase in the credit risk premium, the TAF would have no effect on it. Hence, this is a key question: Was the increase in 
the LIBOR/T-bill spreads at the outset of the financial crisis due to an increase in a liquidity premium or an increase in the credit risk premium. ${ }^{3}$

LIBOR spreads can reflect both liquidity and credit risk premiums. To identify each type of premium, it is necessary to compare rates and rate spreads for banks that are without significant liquidity constraints with comparable rates and rate spreads for market participants that are liquidity constrained. Most investigations of the efficacy of the TAF have relied on an event-study methodology (e.g., Taylor and Williams, 2008a,b, 2009; McAndrews, Sarkar, and Wang, 2008; and Wu, 2008), which has yielded mixed results. Recently, CLR have presented evidence from a six-factor term structure model that indicates that the announcement effect of the TAF had a very large effect on the LIBOR rate. Specifically, CLR conduct a counterfactual experiment and find that the announcement of the TAF reduced the liquidity premium in the 3-month LIBOR rate by 82 basis points relative to what the spread would have been otherwise.

This paper adds to the existing literature in three ways. First, and importantly, I consider the behavior of the LIBOR/T-bill spreads both before and after the TAF announcement because, if nearly all of the change in the LIBOR/T-bill spreads before the TAF can be accounted for by changes in risk spreads, it is difficult to see how the TAF could have generated a large reduction in the liquidity premium. (If the liquidity premium did not increase significantly at the outside of the financial crisis, the announcement of the TAF could not have reduced it dramatically.) Second, I show that CLR's conclusion depends critically on the marked increase in the spreads between AA-rated financial bond rates and equivalent-maturity LIBOR rates immediately following the TAF announcement. I offer an alternative hypothesis for the marked increase in the financial bond/ LIBOR rate spreads and present

\footnotetext{
3 See Krishnamurthy (2010) for a discussion of how an increase in credit risk can cause an increase in the demand for liquid assetsthat is, assets that can be converted to cash quickly with no appreciable market risk. However, this effect is endemic to the market and is not unique to banks. Consequently, as I will show, it is reflected in risk spreads generally.
}

a variety of evidence supporting this hypothesis. Finally, I show that nearly all of the behavior of the LIBOR/T-bill spreads both before and after the TAF announcement is accounted for by the risk premium and that when the risk premium is accounted for, the TAF has at most a modest effect on the LIBOR/T-bill spreads.

The remainder of the paper is as follows. The next section briefly reviews the event-study empirical analyses of the effect of the TAF. The third section presents CLR's affine-term-structuremodel approach for analyzing the effect of the TAF. The section shows that CLR's announcement effect depends critically on the marked increase in the spread between rates on (i) highly rated corporate financial bond rates and (ii) equivalentmaturity LIBOR rates immediately following the announcement of the TAF. The fourth section offers an alternative hypothesis for the marked increase in this spread and presents evidence consistent with this hypothesis. An empirical analysis of the effect of the TAF on the LIBOR/ T-bill spreads is presented in the fifth section. The final section offers conclusions.

\section{Event-Study Investigations of the Effects of the TAF}

Taylor and Williams (2008a) were the first to investigate whether the TAF had a significant effect on the LIBOR rate. They investigated the effect of the TAF by regressing the 1- and 3-month spreads between the LIBOR and OIS rates on various measures of counterparty risk and dummy variables for TAF bid submission dates. In all cases considered, the coefficient on the measure of counterpart risk was positive and statistically significant, indicating that some of the increase in the spread was accounted for by risk premiums. The coefficients on the TAF dummy variable were also positive, but not statistically significant. Based on their economic and empirical analyses, Taylor and Williams concluded that increased counterparty risk between banks contributed to the rise in spreads and find no empirical evidence that the TAF has reduced spreads. ${ }^{4}$

4 Taylor and Williams (2008a, title page). 
McAndrews, Sarkar, and Wang (2008) investigate the effect of the TAF on the LIBOR/OIS spreads using a regression methodology similar to that of Taylor and Williams (2008a). However, they suggest that Taylor and Williams's use of the level of the spread in their regressions is valid only under the assumption that the liquidity risk premium falls on a day with a TAF event but reverts to the previous level immediately after the TAF event. ${ }^{5}$ Using the change in the spread as the dependent variable and dummy variables for all of the various auction announcements and operations, they find that the TAF significantly reduced the size of the LIBOR/OIS spreads.

$\mathrm{Wu}$ (2008) suggests that the methodology used by Taylor and Williams (2008a) and McAndrews, Sarkar, and Wang (2008) is problematic because they (i) assume that the TAF had no effect on the spreads other than on event days associated with it, (ii) do not control for systematic counterparty risk among major financial institutions, and (iii) fail to separate the effects of lowering the counterparty risk premiums from those relieving liquidity concerns. ${ }^{6}$

Wu's (2008) approach to analyzing the effectiveness of the TAF differs from the two previous approaches in three respects. First, rather than using a TAF dummy variable for specific event days only, Wu uses a TAF dummy variable that is zero for all days prior to the TAF announcement on December 12, 2007, and 1 thereafter. Wu (2008) argues that because TAF lending was for maturities of 28 days or longer, one would expect that such loans would be able to relieve the financial strains for the duration of the loans-and not simply affect the spreads on specific event days. $\mathrm{Wu}$ also included alternative measures of stock and bond market volatility and the eurodollar rate volatility as well as a mortgage default risk factor in his regression equations. ${ }^{7}$ In contrast to the findings of Taylor and Williams (2008a), Wu finds that the TAF has, on average, reduced the 1-month LIBOR/OIS spread by at least 31 basis

\footnotetext{
5 McAndrews, Sarkar, and Wang (2008, p. 10).

$6 \mathrm{Wu}$ (2008, p. 3).

7 The mortgage risk factor is the first principal component for credit default swap rates for three mortgage companies.
}

points and the 3-month LIBOR/OIS spreads by at least 44 basis points. He also regresses his TAF dummy variable on two measures of systematic risk and, consistent with Taylor and Williams's analysis, finds that the coefficient is positive and statistically significant, suggesting that the TAF has not been able to reduce the counterparty default risk premiums. ${ }^{8}$

A later paper by Taylor and Williams (2008b) responds to criticism by McAndrews, Sarkar, and Wang (2008) and Wu (2008) and others regarding their earlier (2008a) work. First, they show that the spreads between the LIBOR/OIS rates were very similar to the spread between the LIBOR rate and the repo rate on government securities, arguing that the LIBOR/repo spread is a very good measure of interbank risk because it is the difference in rates between secured and unsecured lending between banks at the same maturity. ${ }^{9}$ The close correspondence between these rates suggests that the LIBOR/OIS spreads primarily reflects credit risk and not liquidity risk.

The authors also suggest that one could discriminate between liquidity risk and counterparty risk by comparing the behavior of rates paid to others who lend to banks but are not liquidity constrained, such as the rates paid on certificates of deposit (CDs). Term CDs and term LIBOR loans are alternative ways that banks finance their shorter-term lending. Because purchasers of CDs are not liquidity constrained, there is no reason for $\mathrm{CD}$ rates to increase because of liquidity concerns. However, because these instruments are uninsured, CD rates will rise when market participants believe that lending to banks is more risky. Consequently, the TAF should have no effect on any liquidity premium embedded in CD rates. Taylor and Williams (2008b) note that CD rates have tracked LIBOR rates of comparable maturities very closely, suggesting that liquidity risk is not a significant separate factor driving term lending rates. ${ }^{10}$ They also perform additional regression analysis altering the timing of how the TAF

\footnotetext{
8 Wu (2008, p. 2).

9 Taylor and Williams (2008b, p. 6).

${ }^{10}$ Taylor and Williams (2008b, p. 10).
} 
might affect interest rates and using CD rates based on a broader set of banks; they also conduct regression analysis with the spreads between the $\mathrm{CD}$, term federal funds, and eurodollar rates and the OIS rate (the dependent variable). They find no evidence of a significant effect of the TAF in any of these regressions.

Taylor and Williams (2008b) find that the results using Wu's (2008) TAF dummy variable were fragile. Specifically, the coefficient was large and statistically significant over one sample, but not when the sample was extended. ${ }^{11}$ They also investigate the effectiveness of the TAF using the outstanding TAF loan balance. The estimated coefficients were sometimes negative, but seldom statistically significant.

Finally, the authors find that the results using the first difference of the spread rather than the level of the spread depended critically on the timing of the variable in the regression and on the particular TAF events considered. Noting that the relationship between LIBOR/OIS spreads and various measures of counterparty risk are robust, they conclude that, while other researchers have found significant TAF effects by altering the specification of the empirical equation they originally proposed, these results are sensitive to small changes in specification, measures of the spread, or measures of risk. ${ }^{12}$

\section{THE EFFECTIVENESS OF THE TAF: RESULTS FROM A SIX-FACTOR TERM STRUCTURE MODEL}

CLR use a very different approach, noting that the McAndrews, Sarkar, and Wang (2008) and $\mathrm{Wu}$ (2008) conclusions about the effectiveness of the TAF using regression analyses of Taylor and Williams (2008a,b) are sensitive to only small differences in the specifications of their regression equations. ${ }^{13}$ Specifically, they analyze the effectiveness of the TAF by estimat-

\footnotetext{
${ }^{11}$ Also see Taylor and Williams (2009), which reflects work from their two 2008 papers.

12 Taylor and Williams (2008b, p. 20).

${ }^{13}$ Christensen, Lopez, and Rudebusch (2009, p. 4).
}

ing a six-factor arbitrage-free term structure model based on a Nelson and Siegel (1987) yield curve. There are three Nelson-Siegel factors for Treasury yields, two Nelson-Siegel factors for bank bond yields, and a single LIBOR factor. They estimate the model using weekly data over the sample period January 6, 1995, to July 25, 2008. They note that their LIBOR factor changed significantly immediately following the announcement of the TAF (December 14, 2007), as did parameters of their model that involve the LIBOR factor. They then conduct a counterfactual experiment to quantify the effect of the change in the model's behavior for the 3-month LIBOR rate. Specifically, they fix the mean of the LIBOR factor at its preannouncement level and leave the other factors unchanged. Their counterfactual experiment suggests that the 3 -month LIBOR rate would have averaged about 80 basis points higher without the TAF. ${ }^{14}$

Given the sensitivity of the regression approaches to the specification of the equations and other issues, CLR's counterfactual result constitutes the most compelling evidence that the TAF had a significant effect of reducing the LIBOR spreads. Consequently, it is important that this evidence be analyzed carefully. Particularly important is that CLR's counterfactual result depends critically on their LIBOR factor, which is based on the spreads between the 3-, 6-, and 12-month LIBOR rates and rates on AA-rated corporate financial bonds with the same maturities. Their factor differs little from the first principal component obtained from these spreads. Given that CLR assume that the LIBOR is independent of the other five factors, this result is not surprising.

Figure 2 shows CLR's factor and the first principal component of the three rate spreads. The vertical line denotes December 14, 2007 (the week of the TAF announcement). The two factors are very similar. Most important is the fact that both decline markedly immediately following the announcement of the TAF. The marked decline in the LIBOR factor is a consequence of the AArated corporate financial bond rates declining relatively less than equivalent-term LIBOR rates

\footnotetext{
${ }^{14}$ Christensen, Lopez, and Rudebusch (2009, p. 29).
} 
Figure 2

\section{CLR LIBOR Factor and the First Principal Component}

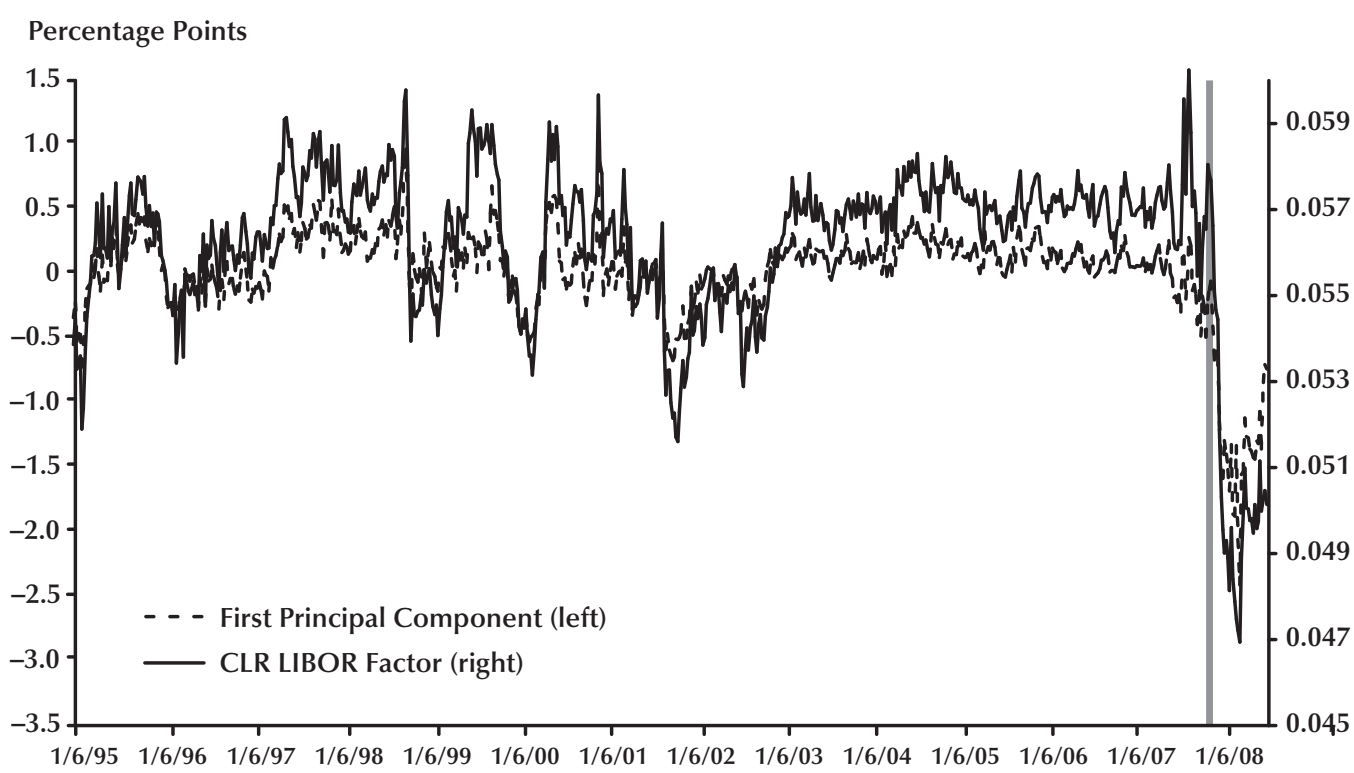

\section{Figure 3}

\section{3-Month AA-Rated Corporate Financial Bond and LIBOR Rates and Their Spread}

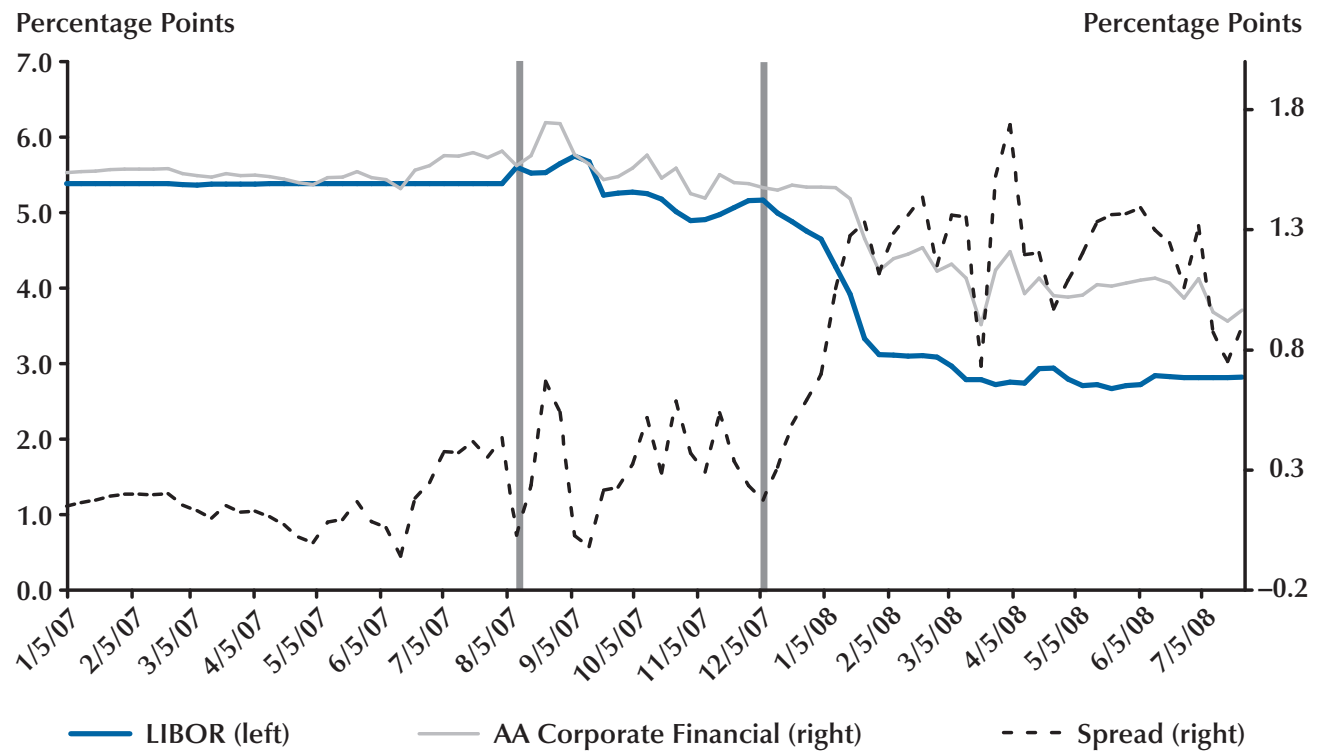




\section{Figure 4}

\section{3-Month CD and LIBOR Rates and Their Spread}

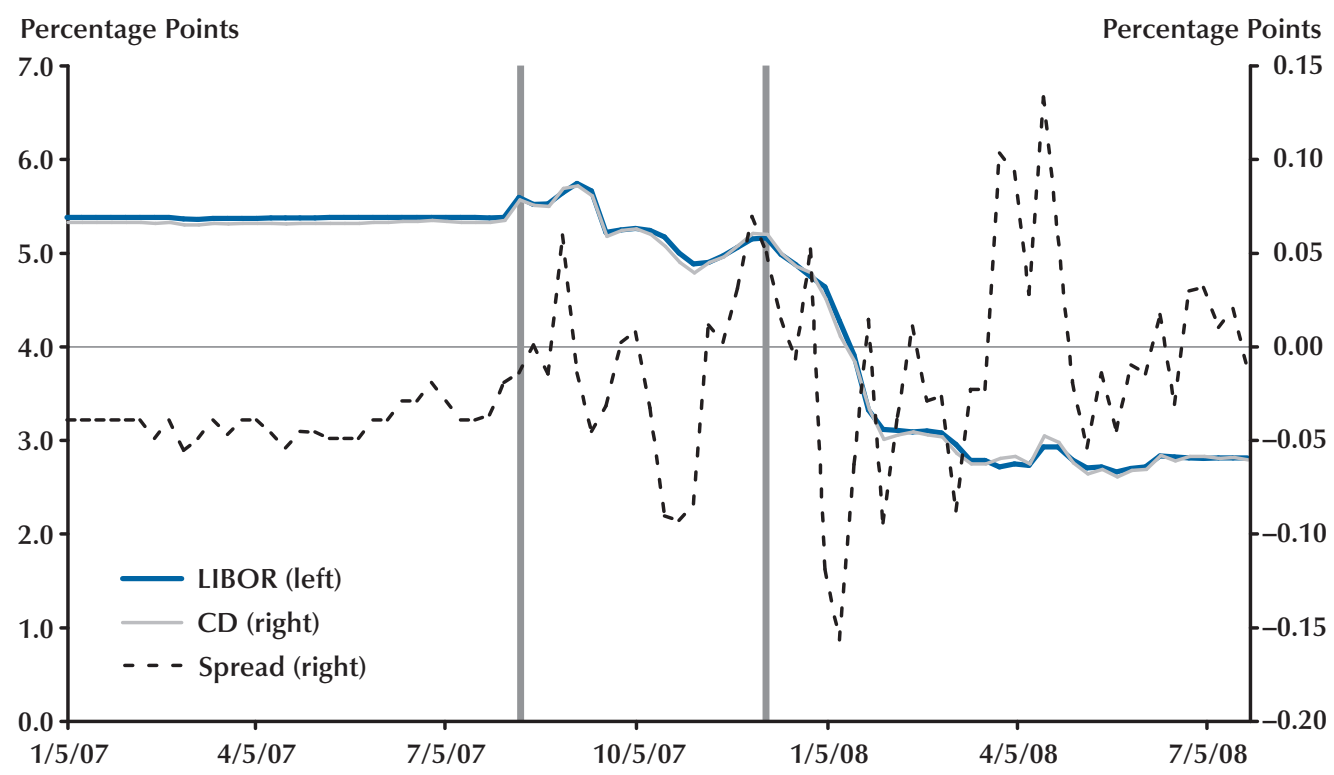

immediately following the TAF announcement. This is illustrated in Figure 3, which shows the 3-month AA-rated corporate financial bond rate, the 3-month LIBOR rate, and their spread weekly from January 5, 2007, through July 25, 2008. The first vertical line denotes the week of the onset of the financial crisis; the second denotes the week of the TAF announcement. Both rates fell on the TAF announcement, but the LIBOR rate declined more than AA-rated corporate financial bond rates, so the spread increased. ${ }^{15}$

Because this marked and very persistent increase in the spread of AA-rated corporate financial bond rates over LIBOR rates is responsible for CLR's counterfactual result, it is important to understand why highly rated corporate financial bond rates increased relative to LIBOR rates following the TAF announcement. CLR suggest that this decline in LIBOR rates relative to financial bond rates is due to a marked reduction in the

${ }^{15}$ The behavior of the 6- and 12-month spreads is very similar to that of the 3-month spread. Indeed, the first principal component of these three spreads accounts for 84 percent of the variance of the three spreads. liquidity premium that banks required to lend in the interbank market. Specifically, CLR suggest that the bank bond rates are derived from debt obligations issued to a broad class of investors that overwhelmingly consists of nonbank institutions. While these two classes of lenders most likely attach similar probabilities and prices to credit risk, they likely have different tolerances for liquidity problems. ${ }^{16}$ That is, the spread widened because of a marked decline in the liquidity premium in the LIBOR rates relative to AA-rated corporate financial bond rates.

There are two reasons to be skeptical of CLR's interpretation. First, if the sharp increase in the spread of AA-rated corporate financial bond rates over LIBOR rates were due to a decline in the liquidity premium required by banks, the same logic would imply that this spread should have declined markedly at the onset of the financial crisis because the liquidity premium required by banks would have increased relative to that of the

${ }^{16}$ Christensen, Lopez, and Rudebusch (2009, pp. 26-27). 
financial bond rate. However, this did not occur. Indeed, Figure 3 shows that, rather than decreasing at the onset of the financial crisis, as CLR's interpretation would suggest, the spread increased; however, it declined subsequently. On average between the onset of the financial crisis and the TAF announcement, the spread changed little from the level for the weeks prior to the beginning of the financial crisis. In short, the spread increased rather than decreased, contrary to the logic of CLR's hypothesis.

Second, CLR's interpretation suggests that there should have been a comparable increase in the spread between the 3-month CD and LIBOR rates. CDs represent loans to banks by a broad class of investors that overwhelmingly consists of nonbank institutions and are a major source of funds for bank lending. Lenders in the CD market are not liquidity constrained and did not acquire liquidity through the TAF. Consequently, we should expect to see a marked decline in the LIBOR rate relative to the CD rate following the TAF announcement. Figure 4 shows the 3-month $\mathrm{CD}$ and LIBOR rates and CD/LIBOR spread weekly for the period January 5, 2007, through July 25, 2008. As before, the first and second vertical lines denote the week of the onset of the financial crisis and the TAF announcement, respectively. The 3-month CD and LIBOR rates are nearly identical before and after the onset of the financial crisis and before and after the TAF announcement. The variability of the CD/LIBOR spread increased with the onset of the financial crisis, but there was virtually no change in the average spread, which was -4 basis points before the financial crisis and -1 basis point after the TAF announcement.

\section{AN ALTERNATIVE HYPOTHESIS FOR THE BEHAVIOR OF THE CORPORATE FINANCIAL BOND/ LIBOR SPREAD}

This section offers an alternative hypothesis for this marked change in behavior of the AA corporate financial/LIBOR spread following the
TAF announcement, which I call the increasedrisk-premium hypothesis (IRPH). ${ }^{17}$ Specifically, it is possible that the market participants interpreted the Fed's announcement of the TAF as an indicator that the financial crisis was more serious than previously thought. The IRPH seems particularly credible given that the Bank of England, the Swiss National Bank, the Bank of Canada, and the European Central Bank announced measures designed to address elevated pressures in shortterm funding markets on the same day. If market participants believed these announcements signaled that the financial crisis was worse than previously thought, the TAF and other announcements could have caused a reassessment of the credit risk of financial firms, increasing the spread between corporate financial bond rates and LIBOR rates.

\section{Evidence of the IRPH: The Behavior of Risk Spreads}

The IRPH is supported by the fact that spreads between corporate financial and non-financial bond rates and the LIBOR rate increased following the TAF announcement. Figure 5 shows the spreads between 3-month (i) AA-rated corporate financial, (ii) AA-rated corporate industrial, and (iii) BBB-rated corporate industrial weekly bond rates and the 3-month LIBOR rate weekly over the period January 5, 2007, through July 25, 2008. The vertical lines denote the onset of the financial crisis and the TAF announcement, respectively. The spreads initially declined with the onset of the financial crisis and the industrial spreads declined prior to the TAF announcement, while the AA-rated corporate financial bond spread remained relatively stable at about 50 basis points. All three spreads increased following the TAF announcement. Moreover, all three spreads increased by similar amounts between the week

\footnotetext{
${ }^{17}$ There were reports that the LIBOR rate (which is obtained from surveys) was understating the rate that banks were actually paying in the interbank market during the financial crisis (e.g., Mollenkamp and Whitehouse, 2008). Kuo, Skeie, and Vickery (2010) provide evidence supporting these claims. However, their estimates of the degree of understatement during this period is not large enough to account for CLR's findings.
} 


\section{Figure 5}

\section{Spreads Between the 3-Month AA-Rated Corporate Financial and AA-Rated and BBB-Rated Industrial Bond Rates and the 3-Month LIBOR Rate}

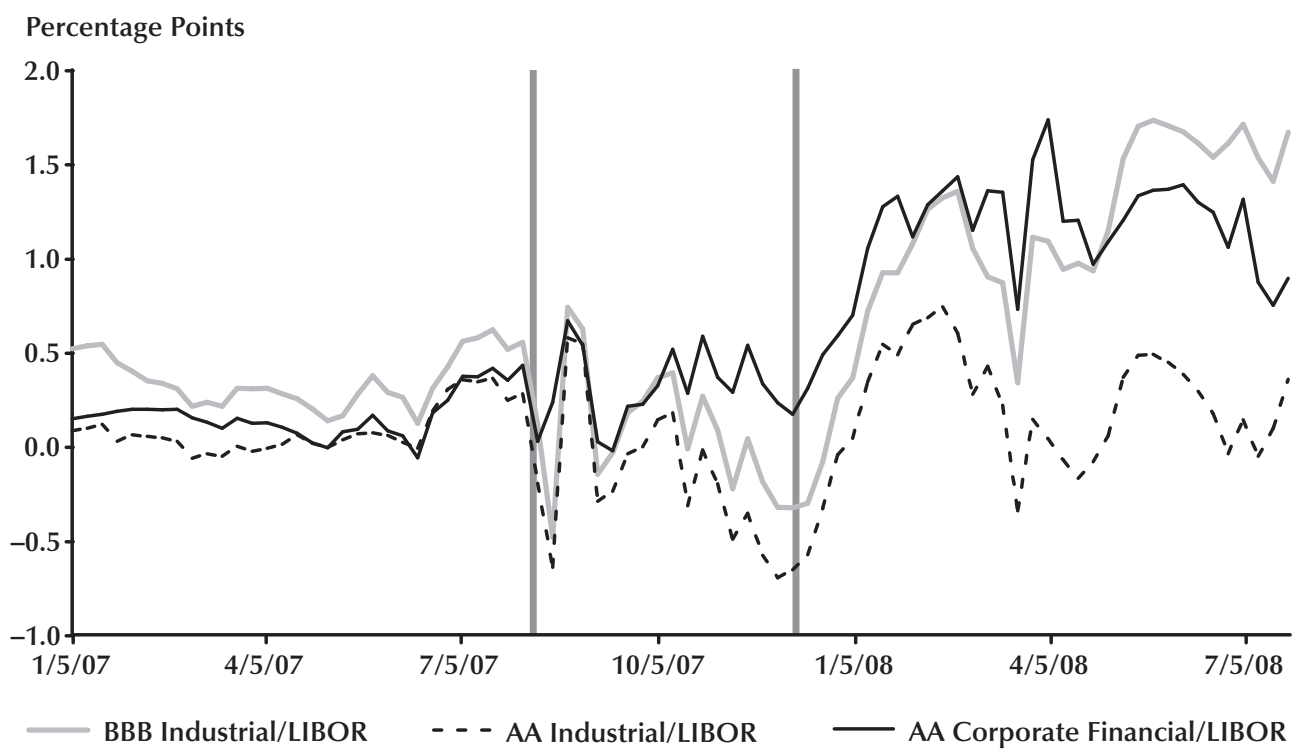

of the announcement and the week of January 25, 2008: The AA corporate financial/LIBOR, AA industrial/LIBOR, and BBB industrial/LIBOR spreads increased by 102, 123, and 106 basis points, respectively. The similarity in the behavior of the spreads before and after the TAF announcement strongly supports the IRPH. As noted above, if the announcement was taken as an indicator that the financial crisis was worse than previously thought, credit risk premiums would have increased, which they did. Indeed, not only did all of these corporate bond rates rise relative to the LIBOR rate, but the spread between $\mathrm{BBB}$ and AA industrial corporate bonds-a commonly used measure of credit risk-also increased dramatically, from 33 basis points prior to the TAF announcement to a peak of 165 basis point in early June 2008. This establishes the possibility that the marked increase in the AA corporate financial/LIBOR spread, which accounts for CLR's counterfactual result, is due to an increase in the risk premium rather than to a decrease in a liquidity premium, as they hypothesize.
Evidence of the IRPH: The Behavior of Corporate Financial and Bank Bond Spreads

The IPRH is also consistent with the relative behavior of corporate financial and bank bond rates. Figure 6 shows the spread between 3-month AA-rated corporate financial and AA-rated bank bond rates. The data are weekly over the period January 5, 2007, through July 25, 2008. The vertical lines denote the onset of the financial crisis and the TAF announcement, respectively. The spread averaged a few basis points in early 2007 and rose on news of subprime mortgage problems. The spread increased further following the onset of the financial crisis, averaging about 10 basis points before the financial crisis and 49 basis points from the onset of the financial crisis to the week prior to the TAF announcement. The spread increased further following the announcement before declining in June 2008. The behavior of the AA corporate financial/AA bank bond spread is consistent with the IRPH for two rea- 
Figure 6

\section{3-Month AA Corporate Financial/AA Bank Bond Spread}

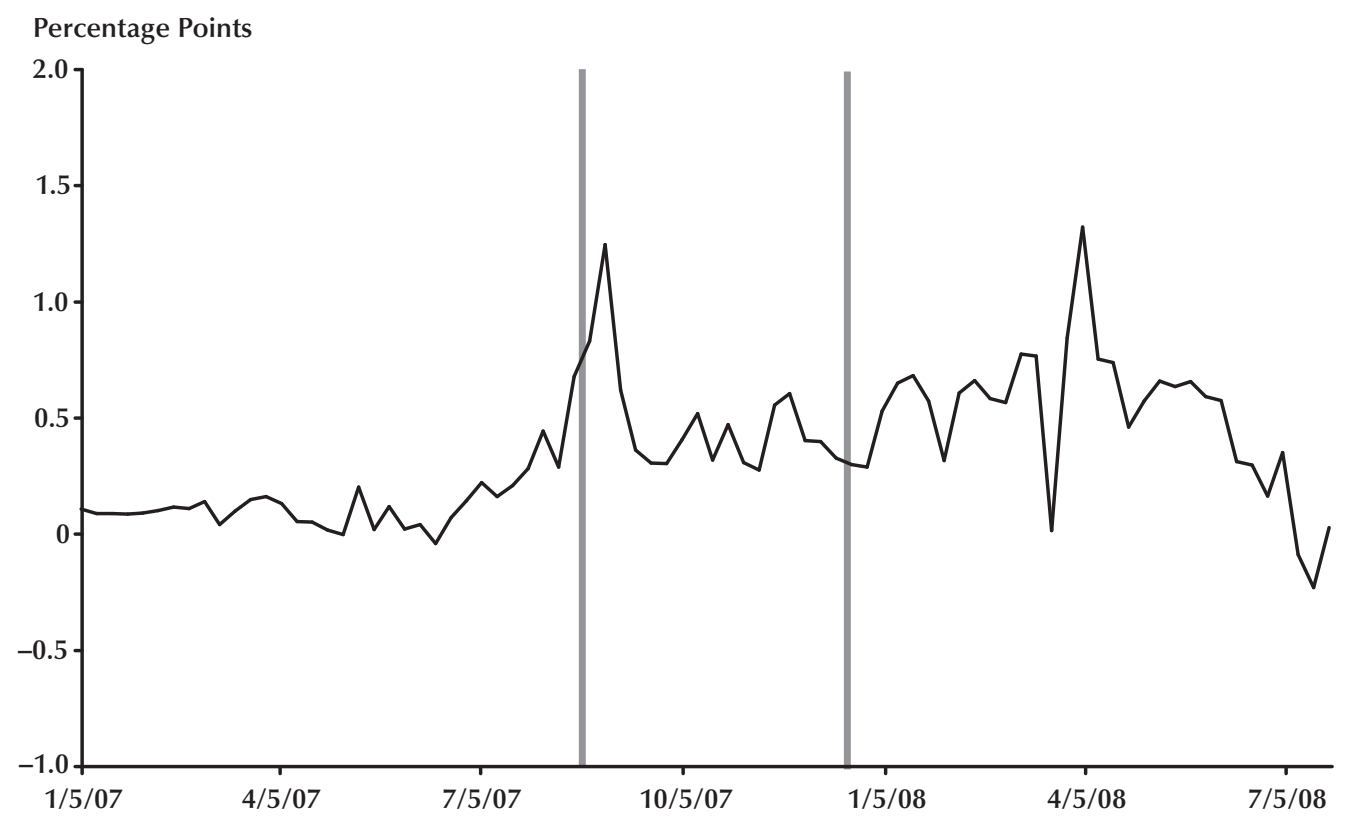

sons. First, the implicit guarantee to bank investors associated with "too big to fail" was initially thought not to apply to non-bank financial corporations, at least before the Bear Sterns bailout. Second, financial corporations had greater exposure to mortgage-backed securities (MBS) than did banks generally. ${ }^{18}$ For both of these reasons, it is reasonable to expect that corporate financial bond rates would rise relative to bank bond rates.

\section{Evidence of the IRPH: CLR's LIBOR Factor and Risk Spreads}

The analysis above strongly suggests that CLR's LIBOR factor reflects a marked change in the risk premium rather than a marked change in a liquidity premium, as they hypothesize. To see how much of the variation in CLR's LIBOR factor can be accounted for by risk premiums,

${ }^{18}$ Of the $\$ 4.4$ trillion of agency and GSE-backed securities held by financial institutions in the second quarter of 2007 , only $\$ 1.1$ trillion was held by banks. the LIBOR factor is regressed on risk premiums reflected in the spreads between BBB-rated and AA-rated corporate bank and industrial bond rates. The spreads are for maturities of 3,6 , and 12 months-the same maturities that CLR used to obtain their LIBOR factor. The sample period begins with the availability of AA-rated bank bond rate data, March 17, 2000. These six risk premiums account for 44 percent of the weekly variation in CLR's LIBOR factor over the sample period March 10, 2000, through July 25, 2008.

To see whether these risk premiums account for more or less of the variation during periods when the LIBOR factor is relatively more variable (especially following the announcement of the TAF), the regression equation is estimated using a rolling window of 60 weeks. Figure 7 presents the rolling window regression estimates of $\bar{R}^{2}$ over the sample period. The data are plotted on the last week in the sample. The vertical line denotes the first sample to include post-TAF-announcement data. The estimates show that the risk premiums account for relatively more of the variation in 


\section{Figure 7}

\section{0-Week Rolling Estimates of Adjusted $R^{2}$ of the CLR LIBOR Factor on Corporate Risk Spreads}

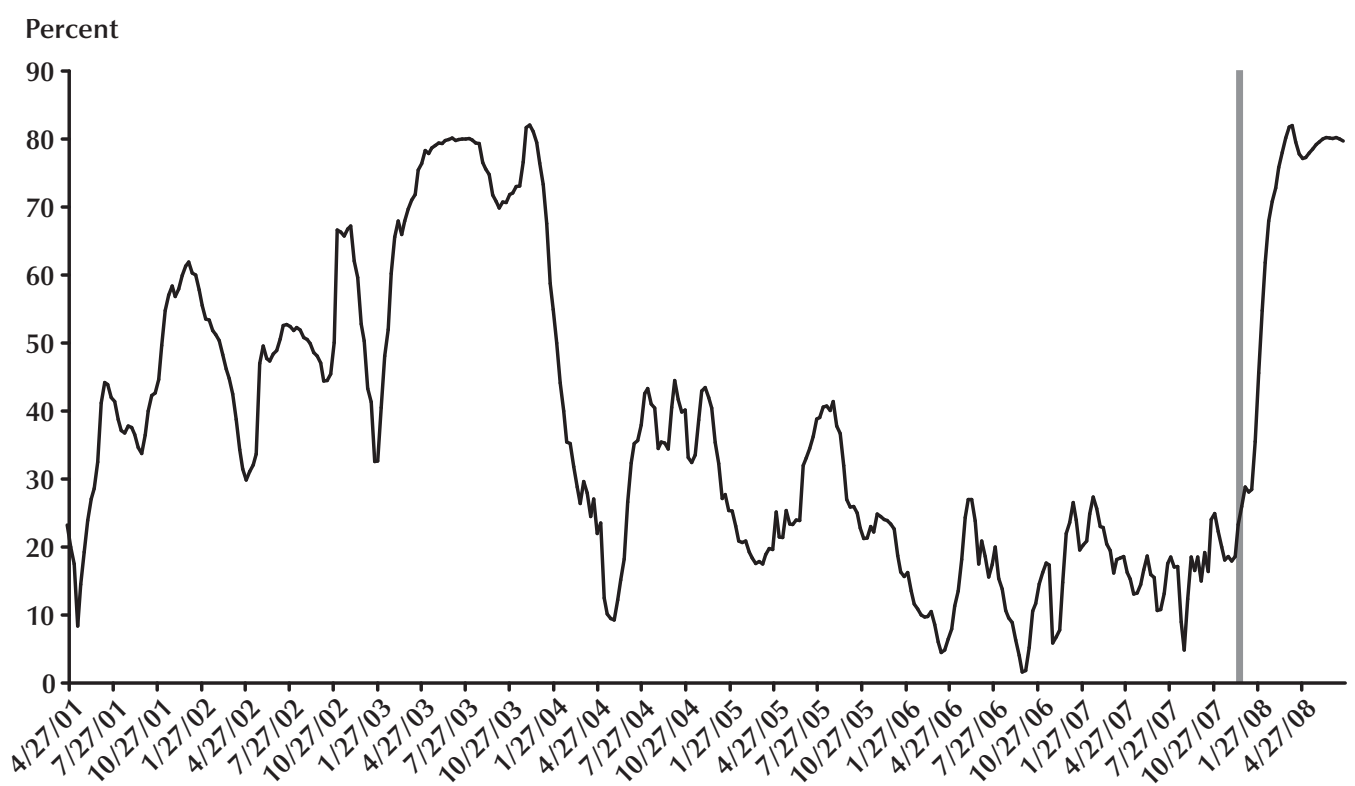

CLR's LIBOR factor when it is particularly variable (see Figure 2). For example, between 2001 and 2003, risk premiums account for over 80 percent of the variation for a period of a year or longer. Importantly, for the issue of whether CLR's counterfactual results are evidence of the success of the TAF in reducing liquidity premiums, the estimate of $\bar{R}^{2}$ increases dramatically when post-TAFannouncement data are included in the sample. The estimate of $\bar{R}^{2}$ peaks at 82 percent for the 60-week period ending April 4, 2008.

It may also be the case that the sharp increase in the spread of LIBOR rates over equivalentmaturity Treasury rates was at least partly due to an increase in the risk premium associated with bank lending. To investigate this possibility, the 3-month LIBOR/T-bill spread was regressed on the same six risk premiums over the same sample period. The risk premiums account for 50 percent of the variation in the LIBOR/T-bill spread over the entire sample period. Figure 8 , which plots the 60-week rolling estimate of $\bar{R}^{2}$ for a regression of the LIBOR/T-bill spread on the six risk premiums, shows that after declining to essentially zero, the estimate of $\bar{R}^{2}$ increased dramatically following the onset of the financial crisis (the first vertical line). It continued to increase to a peak of nearly 70 percent following the TAF announcement (the second vertical line).

\section{EXPLAINING THE BEHAVIOR OF THE LIBOR/T-BILL SPREADS}

The analysis in the previous section suggests that CLR's LIBOR factor is largely accounted for by risk premiums and does not present strong support for the effectiveness of the TAF. However, the evidence using weekly data suggests that the TAF may have been effective in reducing the LIBOR/T-bill spread.

This issue is investigated more thoroughly in this section using daily data using corporate bond/T-bill spreads not previous used in the literature. The corporate bond/T-bill spreads are for corporate bank, industrial, and retail bonds. These spreads are denoted $B T 3, I T 3$, and $R T 3$, respectively. The CD/T-bill and LIBOR/T-bill spreads 
Figure 8

\section{0-Week Rolling Estimates of Adjusted $R^{2}$ of the 3-Month LIBOR/T-Bill Spread on Corporate/T-Bill Risk Spreads}

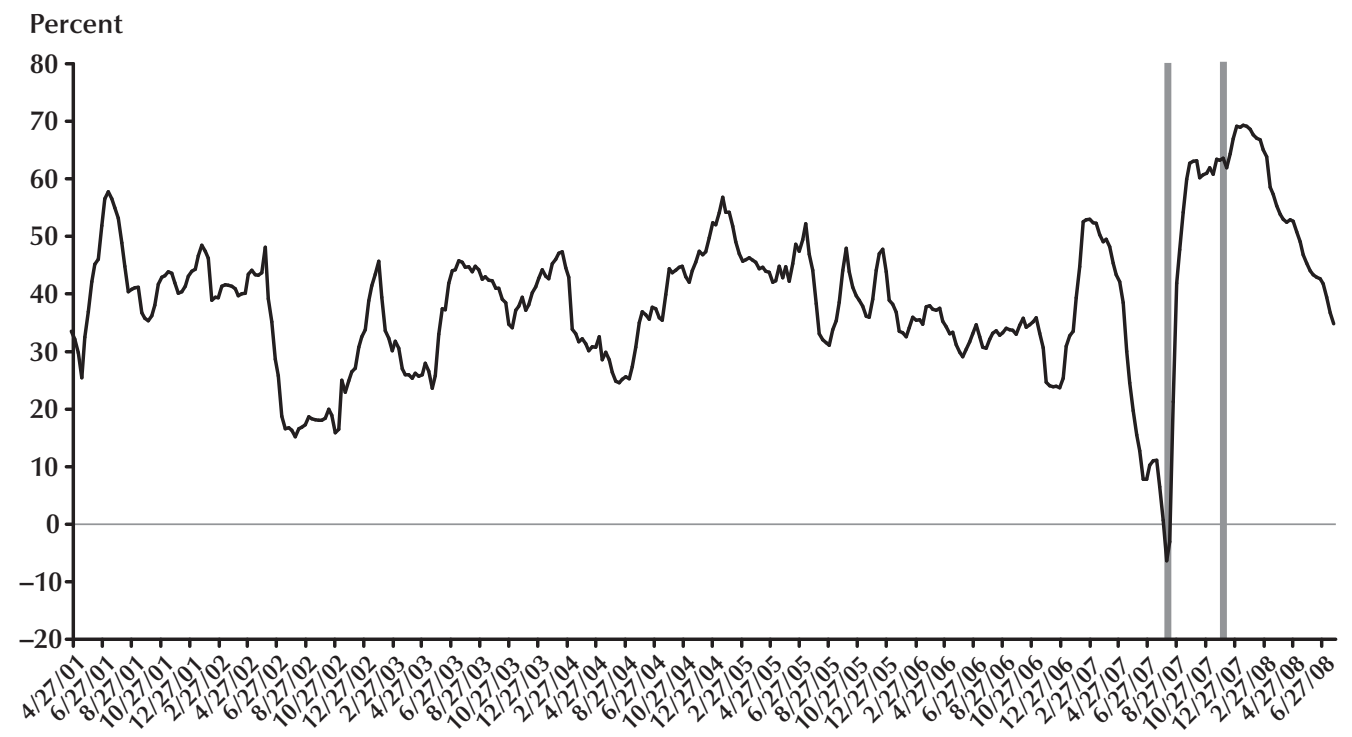

are denoted CDT3 and LT3, respectively. The effect of the TAF is investigated further by estimating the equation

$$
L T 3_{t}=\alpha+\beta_{b} B T 3_{t}+\beta_{i} I T 3_{t}+\beta_{r} R T 3_{t}+\delta \text { DUMVEC }+\epsilon_{t},
$$

where DUMVEC is a vector of dummy variables that reflect important TAF dates used in the previous event-study literature and $\epsilon_{t}$ is an i.i.d. error term. To make the results comparable to the previous event studies, different sets of dummy variables identical to those used by Taylor and Williams (2008ab), McAndrews, Sarkar, and Wang (2008), and Wu (2008) are used. There are six dummy variables. The first five are those used by McAndrews, Sarkar, and Wang (2008): The dates of international announcements related to the TAF (ANI), domestic TAF announcements $(A N D)$, dates when the conditions of the announcement were set $(C O N)$, when the auction took place $(A U C)$, and when banks were notified (NOT). ${ }^{19}$ The sixth dummy variable is that used by $\mathrm{Wu}$

19 These dates can be found in McAndrews, Sarkar, and Wang (2008, Table 1, p. 20).
(2008), denoted $W u$, which is zero before December 12, 2007, and 1 thereafter. The sample period is March 10, 2000, through April 30, 2008. ${ }^{20}$

The results are presented in Table 1 . The $p$-values are based on HAC standard errors. The results in the first two columns use McAndrews, Sarkar, and Wang's (2008) dummy variables. The results indicate that $L T 3$ is significantly related to each of the corporate bond spreads; the coefficient on each bond spread is positive and highly statistically significant. Moreover, the sum of the coefficients is 0.92 and the hypothesis that the sum of the coefficients is 1 is not rejected at the 5 percent significance level. The estimates of the coefficients on TAF dummy variables provide no evidence that the TAF had any significant effect on the LIBOR/T-bill spread: The coefficients on the $A N I$ and $A N D$ dummy variables are positive, but not statistically significant. The coefficients on TAF operation dummy variables are negative,

\footnotetext{
${ }^{20}$ The sample ends on April 30, 2008, to make the TAF sample period similar to that used by McAndrews, Sarkar, and Wang (2008) and $\mathrm{Wu}$ (2008).
} 


\section{Table 1}

The Effect of the TAF on the 3-Month LIBOR/T-Bill Spread

\begin{tabular}{|c|c|c|c|c|c|c|c|c|}
\hline & Estimate & $p$-Value & Estimate & $p$-Value & Estimate & $p$-Value & Estimate & $p$-Value \\
\hline Constant & -0.040 & 0.111 & -0.040 & 0.116 & -0.089 & 0.001 & 0.060 & 0.000 \\
\hline$\beta_{b}$ & 0.415 & 0.000 & 0.414 & 0.000 & 0.547 & 0.000 & -0.014 & 0.229 \\
\hline$\beta_{i}$ & 0.275 & 0.007 & 0.275 & 0.007 & 0.266 & 0.002 & 0.007 & 0.431 \\
\hline$\beta_{r}$ & 0.226 & 0.001 & 0.225 & 0.001 & 0.230 & 0.000 & 0.058 & 0.000 \\
\hline ANI & 0.331 & 0.168 & - & - & - & - & - & - \\
\hline$A N D$ & 0.115 & 0.541 & - & - & - & - & - & - \\
\hline$A N I+A N D$ & - & - & 0.224 & 0.241 & 0.281 & 0.131 & 0.042 & 0.082 \\
\hline CON & -0.005 & 0.968 & -0.004 & 0.975 & 0.096 & 0.377 & 0.016 & 0.350 \\
\hline$A \cup C$ & -0.168 & 0.160 & -0.167 & 0.160 & -0.048 & 0.639 & -0.006 & 0.591 \\
\hline NOT & -0.214 & 0.121 & -0.213 & 0.108 & -0.087 & 0.375 & -0.016 & 0.136 \\
\hline$W u$ & - & - & - & - & -0.340 & 0.012 & -0.031 & 0.058 \\
\hline CDT3 & - & - & - & - & - & - & 0.928 & 0.000 \\
\hline $\bar{R}^{2}$ & 0.764 & - & 0.764 & - & 0.778 & - & 0.995 & - \\
\hline SE & 0.172 & - & 0.172 & - & 0.166 & - & 0.026 & - \\
\hline
\end{tabular}

but not statistically significant. The results in the next two columns show that the conclusion does not change when the $A N I$ and $A N D$ are combined.

There is some evidence that the TAF has been effective in reducing the LIBOR/T-bill spread when Wu's dummy variable is included. The estimate of the coefficient on $W u$ is negative and statistically significant, but the coefficient estimate, 34 basis points, is 10 basis points smaller than Wu's estimate. Moreover, consistent with the findings of Taylor and Williams, the coefficient on $W u$ tends to decline and becomes statistically insignificant as the length of the sample increases. It is also the case that evidence of the effectiveness of the TAF all but disappears when CDT3 is included as a regressor: The estimate is negative and statistically significant at slightly higher than the 5 percent significance level, but the magnitude of the effect is only 3 basis points.

\section{CONCLUSION}

This paper reviews the previous literature on the effectiveness of the TAF in reducing the spread between equivalent-maturity LIBOR and T-bill rates and further investigates the effectiveness of the TAF using weekly and daily data. The previous literature using event-study methodologies finds mixed results. The most compelling evidence for the effectiveness of the TAF comes from CLR's (2009) six-factor term structure model. Performing a counterfactual analysis based on a marked change in the LIBOR factor of their model, CLR indicated that the 3-month LIBOR/T-bill spread would have been 82 basis points higher were it not for the TAF. Noting that CLR's LIBOR factor is based on the spreads between AA-rate financial corporate bond rates and LIBOR rates, I show that these spreads are highly correlated with risk spreads, especially during the post-TAFannouncement period.

I offer an alternative hypothesis for the behavior of the spread between AA-rated financial corporate bond rates and LIBOR rates following the announcement of the TAF. Specifically, I hypothesize that market participants revised up their expectations of the seriousness of the financial crisis in the wake of the TAF announcement and 
the announcements of other central banks. I present evidence from a variety of risk spreads that is consistent with this alternative hypothesis, including the fact that over 80 percent of CLR's LIBOR factor is accounted for by risk spreads during this period. This suggests that much of the effect of the TAF that CLR report is actually due to an increase in the risk premium on financial bonds rather than a reduction in the liquidity premium embedded in LIBOR rates. Moreover, this evidence is consistent with the fact that there was no significant decline in the spread between the AA-rated corporate financial bond rates and the LIBOR at the outset of the financial crisis: If there was no significant increase in banks' liquidity premium, it is difficult to understand how the TAF could have reduced it.

I also show that the majority of the 3-month LIBOR/T-bill spread before and after the TAF announcement can be accounted for by the spreads between financial and nonfinancial corporate bond rates. Further analysis using daily data indicates that controlling for these risk premiums, TAF appears to have had little or no effect on the 3-month LIBOR/T-bill spread. 


\section{REFERENCES}

Bernanke, Ben S. "The Economic Outlook." Testimony before the Committee on the Budget, U.S. House of Representatives, January 17, 2008.

Board of Governors of the Federal Reserve System. Press Release. December 12, 2007; www.federalreserve.gov/newsevents/press/monetary/20071212a.htm.

Christensen, Jens H.E.; Lopez, Jose A. and Rudebusch, Glenn D. "Do Central Bank Liquidity Facilities Affect Interbank Lending Rates?” Working Paper 2009-13, Federal Reserve Bank of San Francisco, June 2009; www.frbsf.org/publications/economics/papers/2009/wp09-13bk.pdf.

Krishnamurthy, Arvind. "How Debt Markets Have Malfunctioned in the Crisis.” Journal of Economic Perspectives, Winter 2010, 24(1), pp. 3-28.

Kuo, Dennis; Skeie, David and Vickery, James. "How Well Did LIBOR Measure Bank Wholesale Funding Rates During the Crisis?” Unpublished manuscript, Federal Reserve Bank of New York, July 30, 2010.

McAndrews, James; Sarkar, Asani and Wang, Zhenyu. "The Effect of the Term Auction Facility on the London Inter-Bank Offered Rate.” Staff Report No. 335, Federal Reserve Bank of New York, July 2008; www.newyorkfed.org/research/staff reports/sr335.pdf.

Mollenkamp, Carrick and Whitehouse, Mark. "Study Casts Doubt on Key Lending Rate: WSJ Analysis Suggests Banks May Have Reported Flawed Interest Data for LIBOR.” Wall Street Journal, May 29, 2008, p. A1.

Nelson, Charles R. and Siegel, Andrew F. "Parsimonious Modeling of Yield Curves.” Journal of Business, 1987, 60(4), pp. 473-89.

Taylor, John B. and Williams, James C. “A Black Swan in the Money Market.” Working Paper Series 2008-04, Federal Reserve Bank of San Francisco, April 2008a; www.frbsf.org/publications/economics/papers/2008/wp08-04bk.pdf.

Taylor, John B. and Williams, James C. "Further Results on a Black Swan in the Money Market.” SIEPR Discussion Paper No. 07-046, Stanford Institute for Economic Policy Research, May 2008b; www-siepr.stanford.edu/papers/pdf/07-46.pdf.

Taylor, John B. and Williams, James C. "A Black Swan in the Money Market.” American Economic Journal: Macroeconomics, 2009, 1(1), pp. 58-83.

Wu, Tao. "On the Effectiveness of the Federal Reserve's New Liquidity Facilities." Working Paper No. 2008-08, Federal Reserve Bank of Dallas, May 2008; http://dallasfed.org/research/papers/2008/wp0808.pdf. 
